\title{
Imaginaciones territoriales, cuerpo y género. Dos escenas en la literatura argentina actual
}

\author{
Territorial imaginations, body and gender. \\ Two scenes from contemporary Argentinian literature
}

\author{
LUCÍA DE LEONE
}

Universidad de Buenos Aires; CONICET; Universidad Nacional de las Artes

Desde el cambio de milenio y en el marco del denominado "giro espacial" en las ciencias Humanas y Sociales, se evidencia en distintas disciplinas y expresiones artísticas un sostenido interés por reconsiderar el espacio en contextos sociopolíticos, culturales y económicos de globalización, donde las correspondencias con el orden nacional son cada vez más difusas, en tanto el mercado, la institución omnipresente, desplazaría a los estados de sus antiguas funciones. Dentro de este vasto panorama, este trabajo pretende acotar esa densa reflexión contemporánea a los modos en que ciertas zonas de la literatura argentina actual establecen nuevas conexiones entre la configuración de espacios rurales del presente con los procesos de representación y validación de los cuerpos. En particular se analizarán en algunos cuentos de Pájaros en la boca de la escritora argentina actual Samanta Schweblin, las configuraciones y los usos diferenciales de los cuerpos en diferentes formas que asume el espacio rural, que se presenta impreciso, desdiferenciado, imaginado, extrapolado, y hasta anómalo al territorio nacional, donde, además, se les aplican a los cuerpos políticas de la vida y de la muerte.

Palabras clave: cuerpo, espacios rurales, Samanta Schweblin, ciencias de la vida.

Since the turn of the millennium and in the framework of the so-called "space turn" in the Human and Social Sciences, there is evidence in various disciplines and artistic expressions of a sustained interest in reconsidering the space in socio-political, cultural and economic contexts of globalization, where correspondences with the national order are increasingly blurred, while the market, the omnipresent institution, would displace the states of his old functions. Within this vast panorama, this paper intends to limit that dense contemporary reflection to the ways in which certain areas of current Argentine literature establish new connections between the configuration of rural spaces of the present and the processes of representation and validation of bodies. In particular, we will analyze in some stories of Pájaros en la boca of the current Argentinean writer Samanta Schweblin, the configurations and differential uses of bodies in different forms assumed by the rural space, which appears vague, dedifferentiated, imagined, extrapolated, even anomalous to the national territory, where, in addition, they are applied to the political bodies of life and death.

Key words: bodies, rural spaces, Samanta Schweblin, life sciences. 


\section{INTRODUCCIÓN}

Ante la insistencia del siglo XIX por la Historia y el tiempo, desde el cambio de milenio y en el marco del denominado "giro espacial" en los estudios en Humanidades y Ciencias Sociales (Gillian 2002; Harvey 2006; Soja 2010), se registra un interés por repensar el espacio en un contexto socioeconómico, geopolítico y cultural global, en el cual las correspondencias con el orden nacional- estatal se vuelven cada vez más difusas y dificultadas. El mundo contemporáneo es el de la hiperconectividad teleinformática, las geopolíticas descentralizadas y nómades, las desorientaciones de género, las imaginaciones territoriales, el resquebrajamiento de los antiguos binarismos que fueron producto de proyectos civilizatorios y ordenadores de la Modernidad (público/ privado; centro/ periferia; nacional/ cosmopolita; urbano/ rural; naturaleza/ cultura; humano/ animal). Ese mundo donde las distancias terrestres son desmaterializadas y acortadas por la virtualización del cosmos global, y donde las formas de habitar los espacios y renegociar las identidades sobrepasan los "mapas-logotipo", esos trazados científicos que surgieron en sintonía con la formación territorial e hicieron a la cristalización oficial de la imaginación geográfica argentina (Lois 2014). Ahora bien, dentro de este vasto recuadro, en que el régimen posindustrial y el fluir global revelan nuevas reparticiones de espacios y distribuciones de significados, y establecen ordenamientos y rearticulaciones de cuerpos, sujetos, formas de vida, poblaciones, pretendo en este trabajo acotar esa densa reflexión contemporánea a los modos en que ciertas zonas de la literatura argentina actual establece nuevas conexiones entre la configuración de espacios rurales con los procesos de representación y validación de los cuerpos. La noción de espacio está cruzada por múltiples dimensiones que exceden lo estrictamente material y, en este sentido, se perfila como una categoría compleja desde la cual tanto dilucidar las formas en que las sociedades se fueron transformando como deducir múltiples problemáticas contemporáneas, entre las que se destacan las relaciones de poder y las diferencias culturales que las políticas neoliberales producen tanto sobre las formas de vida como sobre las formas artísticas. De este modo, las artes y la literatura -la escritura, práctica espacializante (Derrida 1989) - se constituyen en productoras de espacialidad, en creadoras de espacios imaginados.

$\mathrm{Al}$ menos desde comienzos del nuevo siglo, las artes argentinas muestran un interés renovado, progresivo, en temas y problemáticas rurales, que acaso se creían ya obsoletos. En esta dirección, en el ámbito literario argentino se registran hoy múltiples narraciones que vuelven al campo-un espacio generizado como masculino que ha funcionado tradicionalmente como reservorio de los valores patrios y proyectos fundacionales del Estado-Nación (Molloy 2010) - y rediseńan los dispositivos binarios (campo/ ciudad; centro/ periferia; Buenos Aires/ interior; nacional/ internacional) y los paradigmas interpretativos desde los que habían sido leídas, así como descentralizan saberes, prácticas, corporalidades y desacralizan imaginarios modernizadores ancestralmente allí arraigados. Una vasta zona de la literatura argentina del presente, entonces, integrada por escritores y escritoras jóvenes, abre un nuevo espacio ficcional en el que el campo se presenta como categoría polisémica y disponible en la medida 
en que se hacen cargo de temas de urgencia en las agendas políticas y de polémica en el feminismo y recolocan nuevos temas en el paisaje rural actual, el del campo sojizado, cruel, global, sin pastoreo de vacas, plagado de aceiteras, galpones y feedlots. Por tomar tan sólo algunos emergentes, algunas ficciones ubican en centros clandestinos rurales el secuestro y la comercialización de mujeres por redes de trata como en La inauguración de María Inés Krimer, Beya. Le viste la cara a Dios (2013) de Gabriela Cabezón Cámara e Ińaki Echeverría; en otras los espacios semirurales dan lugar a intercambios de roles en las relaciones de género y a la irrupción de masculinidades no hegemónicas como en Las chanchas (2014) Félix Bruzzone y Pequeña Flor (2015) de Iosi Havilio. Al mismo tiempo, Samanta Schweblin en Distancia de rescate (2014), María Inés Krimer con Noxa (2016), Inés Acevedo con Quédate conmigo (2017), Ariadna Castellarnau con Quema (2015), Mariana Docampo con Tratado sobre el movimiento, (2014), Mariela Anastasio con No será lo mismo (2017) insertan fábulas del final (del mundo y de la humanidad) a expensas de la enfermedad agrotóxica, la invasión extraterrestre, la hambruna o la desaparición del cosmos virtual en espacios rurales. A su vez, Cristian Molina con Un pequeño mundo enfermo (2014) y Machos de campo (2017), Iosi Havilio con Opendoor (2006) y Paraisos (2012), y Michel Nieva con ¿Sueñan los gauchoides con ñandúes eléctricos? (2013) instalan relaciones sexo afectivas homoeróticas e identidades disidentes en un campo agotado, en un mundo en vías de desaparición.

Campo y cuerpo, entonces, funcionan como zonas de indagaciones éticas, políticas, y también de preocupaciones estéticas.

Pero ¿cómo aparece representado hoy ese espacio que cuenta con un capital simbólico codificado y que fue uno de los principales engendradores de relatos fundacionales, fábulas nacionales y ficciones identitarias?

Por caso, en sus estudios sobre cuerpo y feminismos, la filósofa chilena Alejandra Castillo (Castillo 2015) identifica cómo en el giro biopolítico actual de las prácticas artísticas, el arte constituye, acaso como foco de resistencia ante las redes del poder neoliberal, las narrativas históricas del universal genérico y los órdenes codificados de opresión, tanto una interrogación constante sobre las formas del cuerpo, los presupuestos sobre la especificidad de "lo humano" y las fronteras entre lo vivo y lo muerto, como una puesta en escena de la precariedad de la propia vida.

Por lo demás, si, como sostiene Josefina Ludmer (2010: 121-125), para especular territorialmente se necesita de los cuerpos, si no hay corporalidades sin técnica, sin inscripciones que los narren y normativas que los describan, ¿cuáles serían hoy las formas narrativas, disponibles en el repertorio estético y cultural o fraguadas en el presente, para vehiculizar la experiencia de subjetividades contemporáneas sin definiciones estables y desplazadas hacia un paisaje social transformado?; y, ¿qué vinculaciones despiertan los espacios rurales con la aparición y el tratamiento de cuerpos que surgen como objeto y producto de las nuevas ciencias de la vida -las biotecnologías- en el marco de las sociedades actuales?

En este trabajo propongo examinar las configuraciones y los usos diferenciales de los cuerpos en espacios rurales imprecisos, desdiferenciados, imaginados, y hasta anómalos 
al territorio nacional, donde se les aplican políticas de la vida y de la muerte, en un conjunto de relatos del libro de cuentos Pájaros en la boca de la escritora argentina actual Samanta Schweblin (2012).

\section{LA PLANIFICACIÓN DEL DESTINO}

Las formas políticas de configuración de los sujetos y el armado de nuevas alianzas entre seres humanos y sus otros, conforme a la administración de los cuerpos, el espacio y las vidas, aparecen como recurrencias en la producción de Samanta Schweblin. Su novela Distancia de rescate (2014) puede leerse como una ficción del campo argentino agrotóxico del presente y de los efectos que las políticas de la muerte imponen sobre las superficies corporales; allí vemos cómo las biotecnologías de la producción agrocapitalista global están al servicio de una búsqueda y un distribución determinadas: la inmunidad para las semillas y las futuras cosechas, y la desprotección de las vidas humanas, que se intoxican, se deforman, se contaminan, se enferman, se desvinculan o se asocian en poblaciones de contagio, se mueren. En la novela se deja ver, entonces, el funcionamiento de las biotecnologías en tanto principio de selección y clasificación sobre qué vidas son las preservables y cuáles son las abandonadas, o directamente impulsadas a la muerte.

Tanto la novela como los cuentos "En la estepa" y "Conservas" del volumen Pájaros en la boca entrecruzan formas del espacio rural siempre distópicas -el campo tóxico, estepas alejadas e infecundas, jardines-réplica de aire puro incrustados en la ciudad, respectivamente- con la representación de nuevas maternidades que cuestionan imaginarios y modelos hegemónicos, regulados tanto por una economía de los afectos (sintetizada en la incondicionalidad, la abnegación) como por protocolos de la ley natural sustentados en la confianza sobre el núcleo biológico de lo humano (la fórmula orgánica fecundación, reproducción biológica, alumbramiento). Si como propuso Nora Domínguez en su ensayo sobre la maternidad en la literatura argentina (Domínguez 2007: 10) el discurso de las madres es, en términos generales, un discurso regulado y desplegado por la voz de los hijos y de las hijas que creó modelos de lo materno -con la excepción que representó en la cultura argentina la "toma de palabra" de las Madres de Plaza de Mayo-, Samanta Schweblin construye "ficciones maternas" desplazadas, en las que son las propias madres las que se narran a sí mismas, en primera persona, más allá del principio de intensidad del cara a cara para dar lugar a otros modos del encuentro, otras maneras de vinculación corporal y otras formas de la circulación de los afectos entre madres e hijos.

\subsection{Escena I. La fiesta del monstruo}

El cuento "En la estepa" está narrado por una primera persona femenina, Ana, que forma junto con Pol una comunidad amorosa donde rige el culto a la planificación. Instalados en la estepa su vida cotidiana está acompasada por el ritmo de las listas y la 
dinámica de la repetición. La estepa aparece como una zona rural extraña, alejada de los poblados, no ubicable en los mapas, con puntos de referencia difusos para su exacta localización; un bioma extraño al territorio argentino, caracterizado por la aridez de los suelos, la única compañía de arbustos secos y la apariencia de un desierto frío.

En la rutina de la estepa nada se sale de lo apuntado: horarios, compras, prácticas; la única comunicación con el exterior coincide con los viajes de Pol al pueblo para entregar sus artículos de divulgación científica que versan sobre insectos e insecticidas a revistas del agro, y para proveerse de productos y alimentos.

De inmediato, esta trama que parecía sencilla se torna, como la misma protagonista, desesperada. A esa estepa, donde la vida sí que es difícil, sólo se va con un proyecto sustancial que avale el costo del aislamiento y del acatamiento de las leyes del lugar. En el marco de una estrecha fusión entre hábitat (aridez) y corporalidades (infertilidad), los personajes oponen sus resistencias a los que les tocó en el reparto de lo biológico, y producen una zona monstruosa por fuera de los dispositivos de sujeción y normalización, de los reconocimientos, las clasificaciones y las regulaciones médico-legales; $\mathrm{y}$ al hacerlo, inauguran un horizonte de politización en el límite de la propia vida.

En la unión amorosa de Ana y Pol, la búsqueda desenfrenada por la fertilidad, que en primera instancia acaso vincularíamos al hecho de lograr un embarazo humano, va enrareciendo el clima del relato mediante la práctica del ritual y un eficaz tratamiento del suspenso:

Oscurece tarde en la estepa, lo que no nos deja demasiado tiempo. Hay que tener todo preparado: las linternas, las redes. Pol limpia las cosas mientras espera a que se haga la hora. Eso de sacarles el polvo para ensuciarlas un segundo después le da cierta ritualidad al asunto, como si antes de empezar uno ya estuviera pensando en la forma de hacerlo cada vez mejor, revisando atentamente los últimos días para encontrar cualquier detalle que pueda corregirse, que nos lleve a ellos, o al menos a uno: el nuestro. (Schweblin 2012:170).

Se trata de la preparación de una cacería, que solo puede darse campo adentro, en determinados momentos de la noche y conforme a los formulismos de un plan amateur. ¿Pero a quién se sale a cazar de noche, equipados con redes, linternas, en mitad de ese campo frío, árido, desolado, según la reglas que estipulan un varón y una mujer desesperados, tras el agotamiento de todas las recetas probadas para esa forma de la fertilidad?

La indistinción de "aquello" que hay que atrapar entre los arbustos de la estepa y antes del amanecer opera en diferentes niveles: en el de una superficie corporal que oscila entre lo humano, lo animal, lo no humano, que alcanza por momentos a Pol, el cazador que "se convierte en una especie de animal de caza" (Schweblin 2012: 171); en el de la dimensión que fusiona lo real con lo onírico como cuando Ana, agotada, cabecea y sueña con cosas que le parecen fértiles; en el de la inscripción territorial: los de la estepa son "iguales a los de la ciudad, sólo que quizá más rústicos, más salvajes" (Schweblin 2012: 171); 
y en el del plano de la lengua que abunda en indeterminaciones gramaticales. Así como la fertilidad en tanto potencia aparece emplazada en sitios quiméricos, muchas veces no tangibles (en sueńos, en planes, en proyecciones) y es de orden conjetural (hipótesis y recetas), proliferan los pronombres indeterminados y las formas neutras ("ni uno ni otro", según la procedencia latina de la expresión "ne uter, utra") para referir al objeto de la caza y de las planificaciones de fecundidad: "nos pareció ver algunos" (Schweblin 2012: 170), "algunas veces conversamos sobre esto" (Schweblin 2012: 171).

Un eso, entonces, una suerte de $i t^{l}$ tan esperado como sospechado, tan atrayente como feroz, al que no se le concede estatuto de sustancia (no es sustantivo, no ocurre como núcleo que subordina atributos en un contexto oracional) y hasta se lo elide sintácticamente, acarreando efectos en el orden del sentido, en la semántica: "Siempre me pregunté cómo eran realmente" (Schweblin 2012: 171). Se trata de un indeterminado dentro del espectro de lo viviente, desprovisto de nombre, género, y adscripción a alguna especie.

Ahora bien, la espacialización formal, el corte temporal de la narración -"Ahora estoy sola, mirando la ruta desde la cocina" (Schweblin 2012: 171) - y la inserción de un cambio en la rutina acompañan el viraje que adopta la trama, una vez que todos los planes fracasan. Colapsadas las recetas, frustradas las prácticas para dar con esta extrańa forma de la fertilidad, Pol y Ana apelan a un nuevo procedimiento: integrar nuevos modos del parentesco, sustentados en el contacto con "gente con quien compartir toda esta cosa" (Schweblin 2012: 177), sostenidos en el contagio de un estado de las cosas y de los cuerpos con sus propios regímenes de significación. Es decir, intimar con otros que también fueron a esas tierras "por lo mismo" y lograron el cometido: cazar un "eso" y esconderlo en casa.

La adquisición de estos indeterminados sólo puede concretarse en circuitos al margen de la legalidad, en funcionamiento comunitario e inscriptos en logias cerradas, fraternales, masónicas. Y, quienes accedan a ellos tendrán que transgredir no sólo la ley de los hombres (la que prohíba convivir con los secuestrados de la estepa) sino también la normativa biológica (que los ubique en un más allá o un más acá de lo humano) para la conformación de nuevos agenciamientos, que son territoriales en primer orden (y aquí se emplazan en espacios rurales inubicables) y tienen un devenir, por caso, hallable en otras formas de circulación de los afectos. A través, entonces, de los relatos de las madres en primera instancia, mediante los it se descubrirían no sólo nuevas potencialidades frente a lo viviente sino apropiaciones de los órdenes familiares que redefinen constantemente el estatuto de los hijos.

Si hoy hubiera, como propuso Gabriel Giorgi (2014) nuevas proximidades entre cuerpo humano y vida animal, entendida esta ya no como forma definida, reconocible y ubicable según sentidos normativos y lugares culturalmente pre-asignados sino como

\footnotetext{
${ }^{1}$ El vocablo inglés "it" reúne las valencias de la indeterminación del pronombre personal utilizado para no personas como la de la criatura de la popular miniserie de terror IT (1990), basada en la novela homónima de Stephen King, que representa a una suerte de entidad diabólica cuyas formas son móviles (entre ellas, asume la forma humana de un payaso), y emerge cada determinado tiempo en una zona semi rural pueblerina de Estados Unidos para alimentarse de sangre infantil.
} 
"umbral de indistinción", podríamos considerar, en su misma línea de lectura, a esos otros, sin nominación ni estatuto aún, en términos de un continuum orgánico, afectivo, material, político con lo humano que diseñarían en un futuro nuevas "gramáticas de lo visible" (Giorgi 2014).

La otra pareja, de nombres y costumbres raras, son Arnol y Noel, habitan una casa que parece una vieja hostería de montaña y los invitan a una cena, que más que funcionar como excusa para conocer al "bebé" ya en casa, intercambiar experiencias comunes y adquirir entrenamiento en el arte de conseguir a esos, deviene una fiesta del monstruo.

La comida que antecede al momento dispuesto por los flamantes cofrades para mostrarles "eso" es un ritual más, casi un bautismo de su nueva adquisición; no obstante el plan está otra vez condenado al fracaso. La eterna sobremesa, basada más en sobrevivir a la violencia de la abundancia y a las técnicas caseras de disciplinamiento que en una charla armoniosa, constituye para los invitados una prueba más: después de exuberantes y sofisticados platos, con postres y vinos, le llega el turno a la espera más extrema que se acumula de incertidumbres:

Quiero preguntar cosas, ya mismo: cómo lo agarraron, cómo es, cómo se llama, si come bien, si ya lo vio un médico, si es tan bonito como los de la ciudad. Pero la conversación se alarga en puntos tontos (...) Arnol se ríe, pero en vez de contestar ubica la fuente en la mesa y pregunta a quién le gusta la carne roja y a quién más cocida y enseguida estamos comiendo otra vez (Schweblin 2012: 174-175).

Toda la escena previa al descubrimiento del it está atravesada por la retórica del planeta bebé que Ana despliega en una charla privada con su congénere; interesa si eso es lindo, si duerme todo el día, si come bien, si lo dejan solo, si sonríe, si ya lo vio un médico. Este rancho aparte de las mujeres podría operar como remedo de los cada vez más practicados baby showers, esas preparatorias de la dulce espera que celebran la inminente llegada, en este caso de un $i$, donde prima la complicidad entre pares y se acopian regalos antes pautados para el armado equilibrado del nido. Allí se traen a cuenta, como ocurrencia graciosa, detalles sobre las cacerías y los instrumentos utilizados, como si se trataran de humoradas sobre las inseminaciones o metáforas del coito en días fértiles (la toma de temperatura, el conteo de días según el ciclo menstrual, las posiciones recomendadas, la elección de los días previos o posteriores al 14 para que sea nene y nena):

- ¿Y las salidas? ¿Las cacerías nocturnas?- digo riéndome. ¿Los guantes, las mochilas?

-Nabel se queda un segundo en silencia, sorprendida, y después se echa a reír conmigo. - YY las linternas!- dice ella y se agarra la panza-, ¡con esas pilas que no duran nada! Y yo, casi llorando:

¡¡Y las redes! ¡La red de Pol!

- ¡Y la de Arnol!- dice ella- ¡No puedo explicarte! (...)

-Y la escopeta- vuelve a golpear la mesa-, ¡por Dios, Arnol! ¡Si sólo dejaras de disparar! Lo hubiéramos encontrado mucho más rápido... (Schweblin 2012: 176). 
El desplazamiento que se producía en quién narrara la ficción materna redunda en los principios ya no de gestación de los hijos sino de apropiación de los its, cuya concepción de naturaleza incorpórea o extra-corporal a las madres se consolida en la espera desesperada. En esa escena textual recién referida la gracia prontamente declina, y ante la dilación constante que es norma de la casa donde se cena infinitamente (la carne jugosa, el postre esponjoso, el café de nunca acabar), se impone la ruta del desvío. La única opción de concretar las ansias escópicas sobre el it (tan solo verlo, aunque más no sea de soslayo, es lo que Ana pide) es descarriar: no sólo osar dejar la mesa-imán para ir al baño, como hace Pol, sino redireccionar los pasos desde la derecha, donde está el baño, hacia la izquierda -la sinistra- donde se ve la habitación del hijo, del it. Pese al desvío -de la norma y del caminono se sabe qué pasó, qué se vio en ese instante en que Pol finalmente se enfrenta a eso. La develación que se pretendía visual aparece revestida por la contaminación auditiva: caídas, gritos, muebles corridos, cuerpos embestidos, ruidos de bala. Vuelve a escena la escopeta a la casa, usada antes en la escena de la caza como elemento de resolución por antonomasia, que, sin embargo, ahora nada resuelve.

La finalización del cuento es puro desconcierto, después del episodio Pol y Ana huyen desesperados de allí (la desesperación es leitmotiv en estas subjetividades en tránsito); se desvían de la ruta que los lleva a la casa en la estepa hacia quién sabe dónde ni por qué (¿vuelven a la ciudad también infecunda?, ¿lo que vieron es más de lo humanamente tolerable?), en una escena cinematográfica de escape final, tan vertiginoso como efectista.

El espacio interviene en los procesos de inscripción y sujeción de los cuerpos, entendidos como instanciación del ser viviente (Giorgi y Rodríguez, 2009:10); y así los reconoce como sujetos de derecho o los proscribe al dominio de lo desechable. O, como en este caso y en su versión espacial rural e infecunda, al de la clandestinidad y ausencia de reconocimiento nominal y político respecto de esos otros que están, justamente, en un límite siempre inestable con la vida humana.

\subsection{Escena II. La vida en un frasquito}

Si la trama del cuento anterior se fundaba en la búsqueda exasperada y el afán por agregar y extender el tiempo por medio de alguna forma de la trascendencia de la dupla familiar, el cuento "Conservas" se perfila como su contracara: el relato despliega pura postergación y planificación del futuro a través de la intervención sobre el ciclo natural de un embarazo y la batalla contra los parámetros convencionales de medición de la temporalidad. Nuevamente, aparecen problematizadas las concepciones hegemónicas sobre la maternidad para dar lugar a una ficción materna alejada de sus mitos beneplácitos y entendida también como un accidente que viene a importunar los planes de una pareja heterosexual caracterizada, como la del cuento anterior, por su ambición calculística: "Pasa una semana, un mes, y vamos haciéndonos la idea de que Teresita se adelantará a nuestros planes. Voy a tener que renunciar a la beca de estudios porque dentro de unos meses ya no va a ser fácil seguir" (Schweblin 2012: 33). 
Descomponiendo el tiempo en unidades de medición propias de la gestación (semanas y meses), las preocupaciones de la narradora retoman debates clásicos del feminismo -desde Virginia Woolf, Simone De Beauvoir hasta Margarite Duras y Úrsula K. Le Guin por tomar algunos emergentes- como la ecuación disyuntiva libros-hijos que exigiría una elección sin escalas de grises: o libros o bebés, como si la escritura y la maternidad fueran tareas contrarias o mutuamente excluyentes.

En el cuento de Schweblin, la maternidad, formulada en estrecha relación con el estado de gravidez, posee efectos perjudiciales en las experiencias de la mujer y en las conductas del varón, y genera reacciones de resignación y automatismo en los futuros abuelos, que acarician la panza, hacen regalos, están al pendiente. La fórmula parecería querer decir a mayor avance del embarazo, menos empatía entre los progenitores y se desvirtuaría la imagen de la dulce espera con madre y padre simbióticos (mismos dolores, mismos antojos) hacia una sintomatología del rechazo y la incomodidad. Mientras la protagonista se transforma en un cúmulo de insomnio, blanqueo mental y confusión, cuyo cuerpo se muestra tan poco hospitalario con el feto como con la anatomía y emociones nuevas, Manuel, su pareja, adopta un juego de distancias y descuidos que se expresa mediante sucesivas llegadas tardes, mudez, falta de interés y displicencia.

¿Qué hacer, entonces, con un embarazo que se adelanta, que llega justo entonces cuando los proyectos iban en otra dirección? El procedimiento de develación es similar al del cuento anterior, aun cuando la decisión ya esté tomada se procede por dilación de la intriga y por desvío.

En primer lugar, se produce una nivelación de la posible detención del nacimiento con hechos de la vida cotidiana: ¡cómo es posible que en el mundo de hoy, que hace viable alquilar un coche en un país y devolverlo en otro, descongelar del freezer un pollo, acopiar latas con animales muertos adentro para comer o pagar las cuentas por internet, sea tan difícil alterar la organización de los hechos! ¡Cómo entender que ocurran actos antes imposibles, que incluso pequen de rareza o maravilla y cuenten con protocolos legales, bromatológicos, y sea tan difícil modificar un hecho "trivial" -se dice- en el orden de los días! Pese a la virtud dilatoria de la trama, conocemos que lo que se quiere alterar es ni más ni menos que el tiempo de llegada de un feto en crecimiento, esta vez sí dentro del útero materno, sobre el que inciden dispositivos de fijación de la identidad, como el nombre propio (se llama Teresita, en diminutivo, lo que trae claras reminiscencias cristianas) y la asignación biopolítica de una sexualidad predeterminada (es una nena).

Por otro lado, la decisión tomada para no entorpecer sus proyectos con la anticipación de Teresita es desestructurar el orden temporal humano y rebobinar la gestación, un procedimiento de contramarcha gestacional que no lastimará ni provocará la muerte del feto. No se opta por una interrupción voluntaria del embarazo, sino que se arriesgan a una suspensión temporal del ciclo vital hasta el momento justo: "Es la oportunidad dice la narradora- de seguir en continuado" (Schweblin 2012: 40). Ahora bien, para ello es necesario aplicar el desvío, moverse entre cronologías discontinuadas, correrse de la prescriptiva de los saberes médicos, sus clasificaciones, sus legalidades, y buscar otras 
alternativas que consientan el derecho autoimpuesto de intervención y decisión sobre el hacer vivir: después de visitar obstetras, curanderos, comadronas, chamanes, que les dan respuestas "perversas" o "conformistas", encuentran a un tal Weisman, un austero doctor que no figura en las cartillas de las obras sociales y prepagas, que no posee secretaria y los recibe en un módico consultorio para analizar el perfil de la pareja mediante preguntas inusuales a la consulta y epicrisis médicas. El tratamiento presentado es a puro cálculo: hay que hacer listas, hay que escribir actas punto por punto, hay que establecer pautas. Pero eso no es todo, pues tendrán que volverse competentes en el consumo del healthism; administrar bien el imperativo de la salud constituye un capital valioso para lograr una alimentación, una respiración y relajación deudoras de la meditación, una sociabilidad y conductas, tan saludables como rentables.

De este modo, los personajes del cuento de Schweblin ejecutan lo que Paula Sibilia (2009) identifica como tendencias del nuevo régimen de poder en tiempos de la postorganicidad y el postindustrialismo: de la antigua vigilancia disciplinadora se pasa a una autovigilancia privada: "no podemos arriesgarnos a salirnos ni un segundo del guión" (Schweblin 2012: 38), dice la narradora. Se desechan las tecnologías médicas de normalización respectivas al cuerpo de la embarazada y parturienta, y se opta por el manejo de los propios riesgos, mediante los cuales los individuos se convierten en gestores de sí mismos, sujetos que planifican sus vidas del mismo modo en que un empresario delinea las estrategias de sus negocios, evaluando riesgos, costos y beneficios y haciendo inversiones convenientes: “¡Y qué seguridad tenemos con este tratamiento?" (Schweblin 2012: 36) es la pregunta que acecha a los personajes de Schweblin.

Precisamente, el plan para retroceder el ciclo embrionario no sólo se describe como un experimento selfservice sino como un trabajo. Por un lado, el procedimiento se describe con recursos de la investigación en ciencias duras. La llegada y retención del bebé se expulsan del terreno de lo puramente afectivo (no quedan restos melancólicos) y se los recoloca en un orden discursivo pretendidamente neutral: se plantean objetivos -"sólo un velo me separa de mi objetivo" (Schweblin 2012: 39) - y metodologías para la reversión de Teresita, que iría en sentido inverso a Benjamin Button, de la película homónima, que nace viejo y a medida que crece rejuvenece. La técnica consiste en ingesta de pastillas, desafectivización mediante la graduación de la presencia, el cuidado y las caricias de Manuel, y en deshilar la trama de preparación del nido: en una especie de baby shower al revés, los familiares se reúnen en la casa para llevarse los regalos que le habían hecho a la futura beba, envueltos en los mismos y exactos papeles en que venían.

Por otro lado, se utiliza una retórica proveniente del mundo laboral donde imperan la eficiencia, la eficacia, la infalibilidad, el aprovechamiento máximo del tiempo que incide en el desarrollo de nuevas artes amatorias afines; la lógica de la empresa, entonces, como operador fundamental en la construcción biopolítica de los cuerpos y las formas de vida, y colonizando espacios de la intimidad: la pareja, la casa, el vientre, y hasta el freezer del hogar.

¿Cuál es el objetivo del tratamiento? Detener la evolución del embrión, pero no para provocarle la muerte, antes bien para restar tiempo de crecimiento, para volver atrás 
hasta un estadio vital proclive a la expulsión fuera del vientre, a una suspensión del tiempo y de la vida. Si para que crezca un feto en el útero que presenta algún tipo de retardo madurativo se le indican corticoides y reposo de lado izquierdo de modo que el flujo estimule la alimentación, para que se produzca el movimiento contrario hay que redireccionar y graduar las energías con técnicas de relajación y "respiración consciente" en espacios verdes, transurbanos.

A partir de la puesta en funcionamiento de tecnologías de la perdurabilidad y la conservación -tecnologías de la inmortalidad que se apropian ilimitadamente de lo vivo- el paso del tiempo del relato -a cargo de una primera persona correferencial a la protagonista que es la madre- y del embarazo empieza a contabilizarse en días. Se produce un retorno a lo primitivo, a los elementos naturales (al agua, al aire, a la tierra), que tiene lugar en ambientes rurales incrustados en mitad de la ciudad, como el jardín réplica de airepurismo donde la protagonista se contacta con "el vientre húmedo de la tierra", donde su cuerpo "siente la humedad de la tierra y la energía que lo envuelve" y alcanza "la sensación purificadora, rejuvenecedora, como si el agua o el aire volvieran por sí mismos al sitio en el que alguna vez estuvieron escondidos" (Schweblin 2012: 41).

Este jardín funcionaría como una nueva imaginación territorial en la medida en que anula y/o resignifica el dispositivo antagónico campo/ ciudad y toda la serie de atributos que históricamente recibieron. En el universo referencial de Schweblin se sabe que el campo no constituye una opción para contactarse con la naturaleza escapando de la ciudad pútrida, ni la ciudad representa la cuna de la medicalización que garantice eficacia para la conservación de un embrión por fuera del útero materno. Antes bien, este jardínréplica da cuenta de otras reparticiones espaciales y semánticas, en donde se establecen relaciones no estereotípicas entre espacio y cuerpo, poder, percepciones y afectividades que forman lo materno, como la concepción, la procreación, las filiaciones entre madre e hija y la colocación de los hijos en el orden familiar.

Como si tratara de un parto programado, una vez que la narradora supera el máximo nivel en el tratamiento, llega el día señalado, el que estaba rodeado en rojo en el almanaque de la casa. Mientras Manuel camina nervioso, ella ingresa en estado de preparación, aislada en una de las habitaciones. Esta suerte de parto invertido ocurrirá en la casa; nacer en la casa es una práctica antigua que fue reeditada en los últimos tiempos en parte como alternativa natural ante la medicalización extrema, el poder médico, la violencia obstétrica y las terapias químicas contra el dolor. La sintomatología de la narradora es tan similar a la del primer trimestre del embarazo como a la previa del parto: nauseas, adormecimiento, contracciones, mareos, temor a la muerte. Frente a la planificación estricta, a la pretensión de dominio total sobre la vida humana, se impone una resistencia de lo orgánico, una perseverancia vital de lo vivo, que aquí, aunque tenga la duración de un relámpago, se expresa en el cuerpo fuera de sí, tembloroso, que se escapa por instantes del control y la acechanza.

A partir de entonces se narra la escena de expulsión del embrión mediante la imaginería del parto natural: las arcadas como contracciones cada vez más violentas, la apertura del canal de parto, pero con un desvío fundamental (del útero y la vagina a la 
boca), la sensación inconfundible, que pasa para siempre al cofre de los tesoros, como la de una madre cuando ve por vez primera su creación. Eso, tan pequeño y frágil, que la protagonista escupe suavemente de su boca, se acomoda en un frasco aséptico rotulado que funciona como una miniaturización del quirófano- donde se guarda el embrión para ser criogenizado en el propio freezer de la casa "hasta el momento indicado".

Se trata de una reconfiguración de lo vivo mediante la congelación de embriones artesanal, doméstica y caprichosa, para la que no se utiliza instrumental informático ni se accede a la regulación e intervención de instituciones (bancos de datos genéticos, asociaciones conservadoras, el Estado, la iglesia). Por lo demás, tampoco es una experiencia alineable con las técnicas de fertilización asistida o de conservación de óvulos sobre las que un arsenal legislativo y médico ejecuta sus prácticas correctivas y de preservación, como cuando una mujer enferma requiere de terapias químicas y de radiación que pueden resultar ofensivas o teratológicas para un futuro bebé, o cuando la reserva ovárica está disminuida.

¿Dónde y cuándo comienza la vida humana? Son fundamentos que la ciencia, la religión, el biopoder se disputan desde siempre, y hoy más que nunca con la implementación de las tecnologías de la inmortalidad, entre las que se ubica la criogenética. En este cuento de Schweblin la resolución se hace en casa, con el asesoramiento de un seudo especialista que actúa con lógicas alternativas a las del saber científico-farmacológico, en el marco de circuitos no institucionales y depositando la confianza de la terapéutica en réplicas semiurbanas de ambientaciones campestres que habiliten el contacto con lo natural: el jardin de la vida de "Conservas" emerge como la contracara del campo que mata de Distancia de rescate.

La paradoja interesante que trae este relato es la ambivalencia entre salir y reproducir la lógica del biopoder: en tanto intento de suspender el ciclo vital del embarazo habría un gesto de potencia liberadora, pero la metodología del cálculo y la especulación hacen a una ordenación de la vida según la lógica de productividad del trabajo, funcional a intereses de sistemas capitalistas normativos.

En suma, la rica producción de Schweblin queda librada a diferentes lecturas críticas en tanto sus textos pueden interpretarse como novedosas ficciones maternas que se rebelan a prescripciones de cuerpos, sexualidades, conductas, relaciones sexo-afectivas dispuestas de manera excluyente en relatos hegemónicos; también como nuevas ficciones del campo del presente, incluso como acercamientos y desvíos del fantasy y del terror contemporáneos. Ahora bien, aquí interesó indagar en las representaciones de espacio y cuerpo según las configuraciones de mundos e imaginaciones que vienen despertando muchos de los debates de la coyuntura sociopolítica y cultural, desde leyes o proyectos de leyes -fertilización asistida, nuevas formaciones familiares, aborto, adopción, crioconservación- hasta las ambiciones y el impacto político, ético y religioso-moral de las nuevas ciencias de la vida, que también posibilitan agenciamientos más allá de la herencia biológica que ponen en crisis los límites entre humanidad, animalidad, inhumanidad, poshumanidad. A su vez, el campo, aparece como se dijo como un espacio polisémico, más cercano a las agendas del presente que saldando cuentas pendientes -estéticas, ideológicas- con el pasado, y como un material emergente por donde pasan muchas de las preocupaciones de la producción simbólica contemporánea. 


\section{Obras CITADas}

Braidotti, Rosi. 2015. Lo posthumano. Barcelona: Gedisa.

Castillo, Alejandra. 2015. Imagen, cuerpo. Buenos Aires: La Cebra/ Palinodia.

Citro, Silvia; José Bizerril \& Yanina Mennelli. 2015. Cuerpos y corporalidades en las culturas de las Américas. Buenos Aires: Biblos.

De Leone, Lucía. 2016. "Campos que matan. Espacios, tiempos y narración en Distancia de rescate de Samanta Schweblin”, 452 F. Revista de Teoría de la Literatura y Literatura Comparada 16: 62-76. http://revistes.ub.edu/index.php/452f/article/view/16250.

Domínguez, Nora. 2007. De donde vienen los niños. Maternidad y escritura en la cultura argentina. Rosario: Beatriz Viterbo.

Demaría, Laura. 2014. Buenos Aires y las provincias. Relatos para desamar. Rosario: Beatriz Viterbo.

Gillian, Rose. 2002. "Feminism and Geography: The Limits of Geographical Knowledge". En: M. J. Dear \& S. Flusty, The Spaces of Postmodernity. Oxford: Blackwell. 314-324.

Giorgi, Gabriel. 2014. Formas comunes: animalidad, cultura, biopolitica. Buenos Aires: Eterna Cadencia.

Giorgi, Gabriel \& Fermín RODRÍGUEZ (comp.). 2009. Ensayos sobre biopolitica. Excesos de vida. Buenos Aires: Paidos.

Harvey, David. 2006. Spaces of global capitalism. London, New York: Verso.

Heffes, Gisela. 2013. Politicas de la destrucción / Poéticas de la preservación. Rosario: Beatriz Viterbo.

(ed.). 2012. Poéticas de los (dis)colamientos. Houston: Literal.

Koval, Santiago. 2013. La condición posthumana. Camino a la integración hombre-máquina en el cine y en la ciencia. Buenos Aires: Cinema.

Lois, Carla. 2014. Mapas para la nación. Episodios en la historia de la cartografía argentina. Buenos Aires: Biblos.

Ludmer, Josefina. 2010. Aqui América latina. Buenos Aires: Eterna Cadencia.

Molloy, Sylvia. 2010. "Intervenciones patrias. Contratos afectivos", ponencia presentada en un foro organizado por Mabel Moraña en el XXIX Congreso de la Asociación de Estudios Latinoamericanos (LASA), Toronto, Canadá, octubre de 2010, mimeo.

Schweblin, Samanta. 2014. Distancia de rescate. Buenos Aires: Random House.

Sibila, Paula. 2013. El hombre postorgánico. Cuerpo, subjetividad y tecnologías digitales. Buenos Aires: Fondo de Cultura Económica.

Soja, Edward. 1996. Thirdspace. Journeys to Los Angeles and Other Real-and-Imaginated places. Oxford: Blackwell.

. 2010. “Tercer Espacio: extendiendo el alcance de la imaginación geográfica". En: Benach, Núria \& Abel Albet. Edward Soja: La perspectiva postmoderna de un geógrafo radical. Barcelona: Icaria. 181-209. 
